\title{
Improving Aboriginal and Torres Strait Islander nutrition and health
}

\author{
Amanda J Lee, Dympna Leonard, Aletia A Moloney and Deanne L Minniecon \\ Economic interventions to improve access to healthy food
}

1 oor nutrition is a major determinant of excess morbidity and mortality among Aboriginal and Torres Strait Islander peoples, ${ }^{1}$ contributing to over $16 \%$ of the burden of disease. ${ }^{2}$ In this issue of the Journal (page 549), consistent with the "economics of food choice" theory, ${ }^{3}$ Brimblecombe and O'Dea report that the diet of a remote Aboriginal community was high in energy-dense, nutrientpoor foods - the cheapest options to satisfy hunger. ${ }^{4}$ This energycost differential restricts access to healthy food, and helps explain the persistently poor dietary patterns and deplorable health status of remote Indigenous communities. ${ }^{4}$ Placing nutrition issues in an economic framework highlights the investment required to improve Indigenous nutrition. ${ }^{4}$ But what has been learned to date about where resources should be directed?

Despite the high costs and limited availability of healthy foods in remote community stores, surprising achievements have been made in some areas. Community dietary patterns were found to respond directly to improved stock management and food supply, 5,6 and multistrategy, community-directed nutrition programs in some remote communities resulted in marked and sustained improvements in anthropometrical, biochemical and haematological risk factors for chronic disease. ${ }^{7,8}$ Knowledge gained from such studies has broadened the focus of Indigenous nutrition initiatives to include the "supply side" (improving food quality and access to healthy food in remote communities) as well as the "demand side" (promoting nutrition through behaviour change). In 2003, the FoodNorth study provided a comprehensive analysis of remote food supply issues, barriers and leverage points for improvement. ${ }^{9}$ More recently, the Remote Indigenous Stores and Takeaways Project developed nine practical resources, including a freight-improvement toolkit and a buyer's guide, to assist remote stores to stock, promote and monitor the sale of healthy food. ${ }^{10}$

A major barrier is that community stores are seen as small businesses rather than as essential services, like health and education. Encouragingly, several submissions to the recent House of Representatives Inquiry into community stores in remote Indigenous communities detail specific approaches to secure both health and viable business outcomes. ${ }^{11}$ Remote store groups that combine buying power and operational efficiency (eg, the Arnhem Land Progress Association and the Retail Stores group in Queensland) have shown the benefits of store nutrition policies. ${ }^{9}$ Outback Stores, a company established by Indigenous Business Australia in 2006 , included provision of nutritious food as a key goal, and provides one potential model to support sustainable employment and economic development in independent remote stores. ${ }^{12}$

The National Aboriginal and Torres Strait Islander Nutrition Strategy and Action Plan 2000-2010 provided a broad framework for nutrition interventions, addressing both supply and demand issues. ${ }^{13}$ However, implementation of the strategy has neither been sustainably nor well resourced and remains fractured and opportunistic. Therefore, what is still urgently required is systematic, widespread, sustained implementation of evidence-based nutrition interventions. Brimblecombe and O'Dea now rightly highlight the need to also include innovative economic interventions. ${ }^{4}$

\begin{abstract}
"Best buys" to improve Indigenous nutrition and health
1. Continue and expand the reach of successful interventions Increase demand for healthy food

- Brief nutrition interventions and early interventions in primary care, including "well persons" health checks and follow-up action

- Prenatal, antenatal and postnatal nutrition programs; culturally appropriate infant growth assessment and action programs; and promoting breastfeeding and appropriate introduction of solid foods $^{27}$

- School-based nutrition-promotion projects, and community food-literacy and budgeting projects

Improve supply of healthy food

- Use of resources developed by the Remote Indigenous Stores and Takeaways Project ${ }^{10}$ to improve store management practices, and transport and stocking of healthy food

- Local food gardens and traditional food procurement projects

Increase capacity to achieve the interventions given above

- Train and employ an Indigenous nutrition workforce

- Improve housing, including food-storage, preparation and cooking facilities

- Develop a national, coordinated monitoring and surveillance system for food and nutrition

2. Trial economic interventions for widespread roll-out, if successful

- Food supplementation for women, infants and children

- Free fruit and vegetables for remote schools and other settings

- Freight subsidies for getting basic healthy foods to remote areas

- In-store price "mark-up" of less healthy items, and lower price margins on healthier foods

- Expansion of the current national differential taxation system to further favour competitive retail pricing of healthy foods
\end{abstract}

In Northern Territory communities, it has been estimated that up to $36 \%$ of the family income is needed to purchase food, ${ }^{14}$ which is at least double the proportion required by non-Indigenous Australians. ${ }^{15}$ One of the proposed "Close the Gap" equity targets was that, by $2018,90 \%$ of Indigenous families could access a healthy food basket for under $25 \%$ of their income. ${ }^{16}$ However, nutrition issues were not included in the final National Indigenous Reform Agreement of the Council of Australian Governments.

Globally, the dominant economic intervention affecting food pricing is national taxation on food to raise general revenue. ${ }^{17,18}$ In Australia, the basic foods required to maintain health were mostly exempted from the Goods and Services Tax (GST), and the price of these foods was expected to fall after the introduction of the new tax system in 2000. ${ }^{19}$ However, in Queensland from 2000 to 2001 , the price of a basket of healthy foods increased by $12 \%$, more than twice that of less healthy options. ${ }^{20}$ This highlights the unpredictability of complex economic systems and the need for rigorous testing of economic solutions to increase access to healthy food. ${ }^{18}$ Such testing is imperative within remote communities, but base- 
line data are not readily available as Australia lacks a comprehensive food and nutrition monitoring and surveillance system.

It is also crucial that economic interventions support broader models of sustainable development in remote communities. Potential economic instruments include greater differential national taxation on energy-dense, nutrient-poor food (the "fat tax"), and subsidisation of healthy food through freight, in-store pricing and/ or direct commodity subvention systems. There is a case for combining both approaches ${ }^{17}$ to better influence diet among lower socioeconomic groups ${ }^{18}$ and within relatively closed systems, such as schools and workplaces. ${ }^{17}$ The provision of free fruit in such settings has also produced sustained benefits in some countries. ${ }^{21}$

Improving remote area housing to include infrastructure for storage and preparation of food is also vital; in one study, this was serviceable in less than $6 \%$ of houses. ${ }^{22}$ Local food production, including that of traditional foods, may hold promise in some areas. Training and employment of Indigenous nutrition workers ${ }^{23}$ to deliver services, including budgeting programs like Indigenous FOODcents, ${ }^{24}$ are also required.

Welfare reform and income management programs have great potential in some areas. However, in communities where incomes are quarantined and welfare recipients are required to spend a significant proportion of their income on food and other essentials, good public policy dictates that governments must also ensure that a healthy food supply is actually available and affordable in those communities. For the most vulnerable, food supplementation programs, ${ }^{25,26}$ if desired and controlled by the community, are warranted. The value of such assistance is greatly increased where food costs are high, and can immediately improve recipients' dietary quality. ${ }^{19}$

Within a multistrategy approach, economic interventions tailored to community needs will assist low-income Indigenous Australians in remote communities to obtain the food they need for good health. "Best buys" of such an approach are listed in the Box. Solutions must involve sectors beyond health, including food producers, transporters and retailers, educators, economists and policymakers.

\section{Acknowledgement}

We thank Sharon Laurence, Senior Project Officer, National Aboriginal and Torres Strait Islander Nutrition Strategy and Action Plan, for useful comments.

\section{Author details}

Amanda J Lee, PhD, BSc(Nutr), GradDipDiet, Conjoint Associate Professor, ${ }^{1}$ and Manager, Nutrition and Physical Activity ${ }^{2}$

Dympna Leonard, MPH, BSc(Diet), Public Health Nutritionist,

Early Life Nutrition ${ }^{3}$

Aletia A Moloney, MCommNutr, Senior Public Health Nutritionist ${ }^{3}$

Deanne L Minniecon, MHSc(HealthProm), Senior Project Officer (Indigenous Health Promotion) $^{2}$

1 School of Human Movement Studies, University of Queensland, Brisbane, QLD.

2 Population Health Queensland, Queensland Health, Brisbane, QLD.

3 Tropical Population Health Services, Queensland Health, Cairns, QLD.

Correspondence: Amanda_Lee@health.qld.gov.au

\section{References}

1 National Health and Medical Research Council. Nutrition in Aboriginal and Torres Strait Islander peoples. An information paper. Canberra: NHMRC,
2000. http://www.nhmrc.gov.au/publications/synopses/_files/n26.pdf (accessed Apr 2009).

2 Queensland Health. The health of Queenslanders 2008. Prevention of chronic disease. Second report of the Chief Health Officer Queensland. Brisbane: Queensland Health, 2008. http://www.health.qld.gov.au/cho_ report/documents/2008choreport.pdf (accessed Apr 2009).

3 Drewnowski A, Specter SE. Poverty and obesity: the role of energy density and energy costs. Am J Clin Nutr 2004; 79: 6-16.

4 Brimblecombe JK, O'Dea K. The role of energy cost in food choices for an Aboriginal population in northern Australia. Med J Aust 2009; 190: 549-551.

5 McMillan SJ. Food and nutrition policy issues in remote Aboriginal communities: lessons from Arnhem Land. Aust J Public Health 1991; 15: 281-285.

6 Lee A, Bonson AP, Powers JR. The effect of store managers on Aboriginal diet in remote areas. Aust N Z J Public Health 1996; 20: 212-214.

7 Lee AJ, Bonson AP, Yarmirr D, et al. Sustainability of a successful health and nutrition program in a remote Aboriginal community. Med J Aust 1995; 162: 632-635.

8 Rowley KG, Daniel M, Skinner K, et al. Effectiveness of a community directed healthy lifestyle program in a remote Australian Aboriginal community. Aust N Z J Public Health 2000; 24: 136-144.

9 Leonard D. FoodNorth: food for health in north Australia. Perth: Department of Health, Western Australia, 2003. http://www.healthinfonet.ecu.edu.au/uploads/resources/4053_foodnorth.pdf (accessed Apr 2009).

10 Australian Indigenous HealthInfoNet. Remote Indigenous Stores and Takeaways Project. http://www.healthinfonet.ecu.edu.au/health-risks/nutrition/ resources/rist (accessed Apr 2009).

11 Parliament of Australia. House of Representatives. Inquiry into community stores in remote Aboriginal and Torres Strait Islander communities. Submissions. http://www.aph.gov.au/house/committee/atsia/communitystores/subs.htm (accessed Mar 2009)

12 Outback Stores [website]. http://www.outbackstores.com.au/ (accessed Mar 2009).

13 Australian Government Department of Health and Ageing. National Public Health Partnership. Strategic Inter-Governmental Nutrition Alliance. National Aboriginal and Torres Strait Islander Nutrition Strategy and Action Plan 2000-2010. Canberra: DoHA, 2001.

14 Northern Territory Government Department of Health and Community Services. Northern Territory Market Basket Survey, 2006. Darwin: DHCS, 2007. http://digitallibrary.health.nt.gov.au/dspace/bitstream/10137/136/1/ Market_basket_2006.pdf (accessed Apr 2009).

15 Tsang A, Ndung'u M, Coveney J, O'Dwyer L. Adelaide Healthy Food Basket. A survey on food cost, availability and affordability in five local government areas in metropolitan Adelaide, South Australia. Nutrition \& Dietetics 2007; 64: 241-247.

16 Human Rights and Equal Opportunity Commission. Close the Gap: national Indigenous health equality targets. Outcomes from the National Indigenous Health Equality Summit. Canberra: March 18-20, 2008. http:// www.hreoc.gov.au/social_Justice/health/targets/health_targets.pdf (accessed Mar 2009).

17 Caraher M, Cowburn G. Taxing food: implications for public health nutrition. Public Health Nutr 2005, 8: 1242-1249.

18 Powell LM, Chaloupka F. Food prices and obesity: evidence and policy implications for taxes and subsidies. Milbank Q 2009; 87: 229-257.

19 Australian Competition and Consumer Commission. Report on ACCC price surveys: general survey. Canberra: ACCC Publishing Unit, 2001.

20 Harrison MS, Coyne T, Lee AJ, et al. The increasing cost of the basic foods required to promote health in Queensland. Med J Aust 2007; 186: 9-14.

21 Bere E, Veierød MB, Skare $\varnothing$, Klepp KI. Free school fruit — sustained effect three years later. Int J Behav Nutr Phys Act 2007; 4: 5.

22 Torzillo PJ, Pholeros P, Rainow S, et al. The state of health hardware in Aboriginal communities in rural and remote Australia. Aust $N Z \mathrm{~J}$ Public Health 2008; 32: 7-11.

23 National Nutrition Networks Conference, 2008. Recommendations arising from the National Nutrition Networks Conference. http://www.ruralhealth.org.au/conferences/nnnc2008/NNNCrecommendations.pdf (accessed Mar 2009).

24 FOODcents for Aboriginal and Torres Strait Islander people in WA program. http://www.healthyfuture.health.wa.gov.au/Health_topics/ASTIFOOD/ATSI_FC_Manual.pdf (accessed Apr 2009).

25 United States Department of Agriculture Food and Nutrition Service. Women, infants and children. Alexandria, Va: USDA. http:// www.fns.usda.gov/wic/ (accessed Mar 2009).

26 United States Department of Agriculture Food and Nutrition Service. Supplemental Nutrition Assistance Program (SNAP). Alexandria, Va: USDA. http://www.fns.usda.gov/FSP/ (accessed Mar 2009).

27 d'Espaignet E, Measey ML, Carnegie MA, Mackerras D. Monitoring the "Strong Women, Strong Babies, Strong Culture Program": the first eight years. J Paediatr Child Health 2003; 39: 668-672. 